\title{
An Empirical Study on the Factors of Chinese Urbanization Process and Policy Proposals about the "New-Type" Urbanization
}

\author{
Qinhua Pan, Ruofan Xu \\ Schools of Economics and Management, Tongji University, Shanghai, China \\ Email: pangh4902@126.com, Jimmy Napoleon@hotmail.com
}

Received April 2014

\begin{abstract}
First of all, this thesis will compile negative effects of this process since the reform and opening-up policy was enacted. And then the policy background, the connotation and the main function of new-type urbanization will be introduced. Followed by an empirical study, this thesis will also analyze the main factors of traditional urbanization and make corresponding policy proposals for modern urbanization nowadays.
\end{abstract}

\section{Keywords}

The Factors of Urbanization, the New-Type Urbanization, Empirical Study

\section{Introduction}

With the adjustment of national economic structure, the momentum of Chinese economy is changing from relying on export and investment to domestic demand. Meanwhile urbanization is the most powerful weapon to enhance internal demand. Prime minister Li Keqiang points out that, as the law of modernization development, the urbanization ratio of China will improve continually in future ten or twenty years. A considerable amount of rural remaining labor force and population will transfer to cities each year, which will lead to rapid increase in investment and consumption, and also more kinds of human resources for city development. Some scholars argue that urbanization is one of the three engines of Chinese economic transition: according to the data provided by McKinsey \& Co, the urbanization ratio of China is now at 52.6\% (2013), and will be up to 70\% in 2020. More people transferring to cities means more consumption and more opportunities for employment.

So, this thesis aims to find out the key factors in the process of urbanization in a way of empirical test and analyze the results in order to make some corresponding policy proposals for the new-type urbanization. The structure of this journal is about 4 sections: Firstly, the problem of Chinese urbanization; Secondly, the introduction of so-called "new-type" urbanization; Thirdly, the empirical study of urbanization; Last but not least, the corresponding policy proposals. 


\section{The Problem of Chinese Urbanization}

Lengthways from 1978 to 2011, the urban population of China went from 172 million to 690 million; the ratio was from $17.9 \%$ to $51.3 \%$. Although the level of urbanization was seemingly near to the average of the world, the conflicts and contradictions were more and more non-neglectable.

1) Low-cost and predatory mode

Low-cost way of urbanization, which accelerated the process of population migration, left some problems. The worst one may be urbanization lagged behind industrialization, neglecting the importance of population agglomeration except economy agglomeration. Take the rate (urbanization ratio:industrialization ratio) in 2011 for example, it was 1.1 (51.3\%:46.8\%) compared with 1.95, the average level of the world.

2) For rural residents, the real right of land performs practically no function

This problem included that farmer's land rights was impaired in the past 30 years; the local government finance relied on auctioning lands; the efficiency of land utilization was low; the framework of land law was imperfect.

3) The Urban and rural household registration system

In China, Urban population refers to all people residing in cities and towns including 160 million rural migrant workers (or peasant-workers). However because of the hinder of registration system these workers were not treated equal to other citizens.

4) The imbalance and inharmony of urbanization development

Compared with the west, the east areas were overburdened by rapid urbanization, causing resources of economy and society mismatch. As population was over-intensive, metropolis like Beijing, Shanghai and Guangzhou had a lot of troubles such as water, air, education, healthcare and so forth.

On the other hand, the similar structure of regional economy and the convergence of industrial structure bringing excessive competition lead to lower utility.

5) High level of energy dependence

In future decades, the need for urbanization of iron, copper, chromium, sylvite, oil, natural gas and so on will be rigid, the bulk mineral imports will ascend consistently. Thus the degree of foreign-trade dependence will also become higher.

\section{The Introduction of New-Type Urbanization}

\subsection{The Policy Background}

In the Central Economic Working Conference Dec. 16th 2012, the conclusion of discussion indicates that urbanization is the historic mission of Chinese modernization development and also the way to expand domestic demand, so it's vital and urgent to make urbanization develop in a healthy and ordered way. Meanwhile, the National Planning to Promote the Healthy Development of Urbanization (2011-2020), which is the master planning outline of national urbanization, has already finished and will be published soon.

\subsection{The Connotation and Function of New-Type Urbanization}

1) The connotation

Until now, there are no standard definitions of new-type urbanization. Generally speaking, the new-type urbanization contains four aspects: a) coordinated with the development of industrialization and agricultural modernization; b) adapted to population, economy, resources and environment; c) having equal opportunities for all kinds of cities (Large, medium or small) and towns to blossom; and d) with population aggregation, citizenization and the coordinated development of public service. All in all, the characteristics of new-type urbanization are urban-rural overall development, urban-rural integration, production-city interaction, economization and intensification, ecological and livable, harmonious progress.

2) The function

Firstly, in the macro level of nation, the new-type urbanization is the engine of economic growth.

International experience shows that domestic demand is the endogenous power of economic growth, especially for large countries. It's essential to convert the growth pattern from relying on investment to consumption. But there should be a stage of transition, which means investment and consumption have the same privilege to boost growth in this time. The new-type urbanization will be the key to this kind of transition. 
Then, in the meso level of industry, the new-type urbanization will impulse industrial accumulation and upgrade.

As the advantage (compared with rural areas) of capital technique, transportation, living conditions, human resources, communication etc., a large number of labor force and production activities converge on urban regions. Thus the scale of the urban market increases rapidly, impulsing industrial upgrade continually.

Lastly, in the micro level of economic entity, the process of the new-type urbanization has benefit to improve residents' income, especially for rural residents.

Those people who migrate from countryside to city mostly go in for secondary and tertiary industry, with higher level of salary than what they have earned in rural areas; for citizens, their income can also be improved, as investment and consumption was boosted by those immigrations.

\section{The Empirical Study of Urbanization Influencing Factors}

Past empirical studies on urbanization [1]-[3] were mostly based on the analysis of time-series, and the data covered both national level and some specific administrative districts' level.

While, this thesis will use the panel data with the model of two-way fixed effect [4]. Based on the existing achievements by other scholars, this paper will take a further step to analyze the specific factors of Chinese urbanization, will explain the outcome and will make some policy proposals for the way of future development (the new-type urbanization).

\subsection{Selecting Data}

Considering the availability, the data of this thesis include 28 provinces of China (excluding Chongqing, Hong Kong, Macao, Hainan and Xizang) from 1987 to 2008. The independent variables (explanatory variables $x_{i}$ ) are listed in the following Table 1.

The dependent variable (explained variable $y_{i}$ ) is the urbanization ratio, the ratio of urban population to total population [5].

\subsection{The Outcome of Regression}

As the result indicates, we find that the significant factors of Chinese urbanization include: GDP per capita of provinces, the provincial tertiary industrial structure, household registration system, the way of land-expansion urbanization, economic openness and rural income level of provinces (Shown in Table 2).

\subsection{Analysis of the Outcome}

For the proxy variable of household registration system: peasant-workers (migration), the coefficient of it is significantly positive, which means the increasing number of peasant-workers in cities boost the economic development of cities leading to improve urbanization level, but also they are counted as temporary alien workers of the nominal urban population. This is because hindered by the household registration system, they cannot gain the permanent urban residence certificate (in Chinese it calls: hukou) easily.

The variable of the areas of city (land) represents the way of land-expansion urbanization, the coefficient of it is significantly positive proves that land-expansion was one of the ways to improve urbanization level. Generally speaking, one of the prominent problems or "features" in the process of Chinese urbanization is that the growth of urban built up area is much faster than the gather of urban people apparently. The result of this thesis, the coefficient of land is small but significant, proves this point of view.

The coefficient of GDP per capita (GDPpercapita), one of the four variables of economic development, is significantly positive. So it means increasing the average (not only the aggregate) income level of one region can enhance the urbanization level truly, which fits our instinct.

However, the coefficient of tertiary industrial structure (third_second) is significantly negative, which means at present the tertiary industry in our country hasn't absorbed rural surplus labor force adequately. As many regions of high level tertiary industry in China are the developed areas such as Shanghai, there may be some certain rejective intention against immigrations. At the same time, the primary industrial ratio is not significant.

The economic openness of one region represents the development level and the geographic position of provinces (in China, east areas near the sea are considered more exoteric and developed) indirectly. The coefficient 
Table 1. Selected variables of the factors of urbanization.

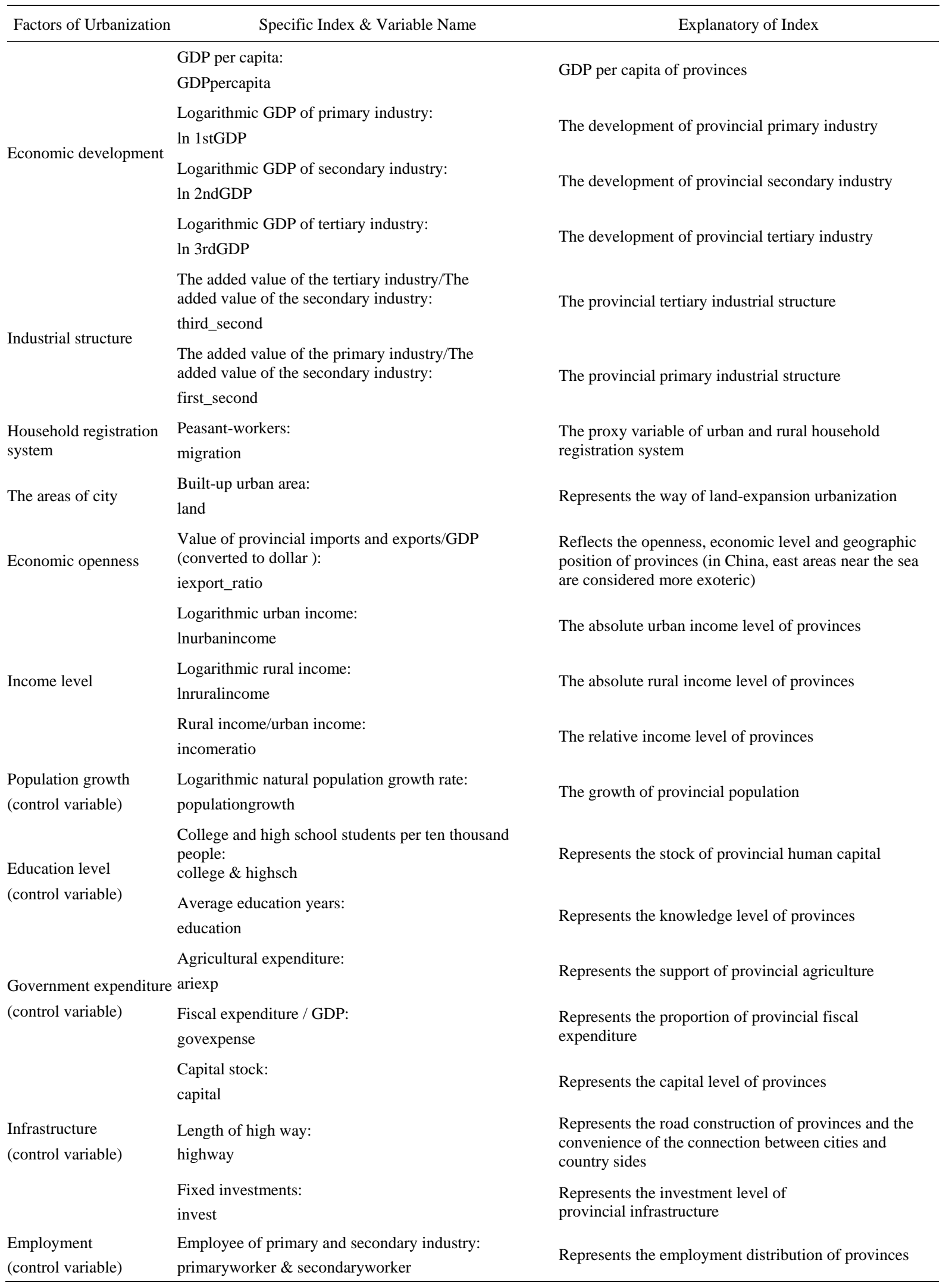


Table 2. The result of the two-way fixed effect model ${ }^{\mathrm{a}}$ (The dependent variable is urban ratio).

\begin{tabular}{|c|c|c|}
\hline & Explanatory Variables $\left(\mathrm{x}_{\mathrm{i}}\right)$ & Coefficient \\
\hline \multirow{4}{*}{ Economic development } & GDPpercapita & $0.00189^{*}$ \\
\hline & $\ln 1$ stGDP & -0.01106 \\
\hline & $\ln 2$ ndGDP & -0.02909 \\
\hline & $\ln 3 r d G D P$ & 0.03954 \\
\hline \multirow{2}{*}{ Industrial structure } & third_second & $-0.06682^{* * *}$ \\
\hline & first_second & 0.01593 \\
\hline Household registration system & migration & $0.00003^{* * *}$ \\
\hline The areas of city & land & $0.00002^{* * *}$ \\
\hline \multirow[t]{2}{*}{ Economic openness } & iexport_ratio & $-0.03387^{* * *}$ \\
\hline & lnurbanincome & -0.15328 \\
\hline \multirow[t]{2}{*}{ Income level } & lnruralincome & $0.07139^{*}$ \\
\hline & incomeratio & -0.05330 \\
\hline \multicolumn{3}{|c|}{$\begin{array}{l}\text { Control variables: agriexp capital highway govexpense college highsch primaryworker } \\
\text { Dummy variables of year: yes } \\
\qquad \mathrm{R}^{2} \text { (within) }=0.991 \text { Number of obs: } 173 \\
\mathrm{R}^{2} \text { (between) }=0.0357 \text { Number of groups: } 26\end{array}$} \\
\hline
\end{tabular}

a. The significance testing used robust standard error. As some observations were missing, the number of obs was low and 2 groups were missing. represents that the estimation is significant at $10 \%$ level, ${ }^{* *}$ represents $5 \%$ and ${ }^{* * *}$ represents $1 \%$.

of it (iexport_ratio) is significantly negative reflects the problem of rejection of outsiders, because rejection of outsiders may downgrade the level of urbanization to some extent.

In the three variables of income level, the coefficient of rural income level (Inruralincome) is significantly positive indicates improving rural income can boost the urbanization ratio. While neither the urban income level (Inrubanincome) nor income gap between urban and rural area is significant.

\section{The Conclusion and Proposals}

The result of regression based on the panel data of 28 provinces from 1987 to 2008 finds out the influencing factors of traditional urbanization to some degree. The main factors are the household registration system, landexpansion mode, GDP per capita of provinces, the tertiary industry ratio, the rejective intention of developed regions and the rural income level. Based on these findings, the following policy proposals are made:

\subsection{Lead by Metropolis, Boosted by Urban Agglomerations and Avoid Relying on Land-Expansion}

Taking advantage of the lead of metropolis to boost the development of urban agglomerations is designed as one of the principle thinking of urbanization. It aims to use urban agglomerations to drive large, medium and small cities and towns to develop coordinately. At the same time, by improving the structure and scale of cities, controlling the number of metropolis and giving priority to developing small towns, satellite towns, towns with professional characteristics, economic growth and urbanization development can be realized.

When it comes to selecting the way of urban pullulation, it's necessary to avoid traditional expansion mode of enclosure. As is analyzed before, land-expansion did play a vital role in the past process of urbanization. However, with the severe lack of land resources and agricultural land this extensive form of enclosure movement needs to be reformed immediately. The goal of urbanization should be changed from expanding the land of cities to improving the hardware and software facilities in city areas, optimizing the urban layout and creating characteristic cities. 


\subsection{To Reform the Household Registration System}

In our empirical outcomes, one of them with Chinese characteristics is the peasant workers who truly have increased the nominal urbanization level (by 2011, the real ratio of urbanization is about 35\% to 36\%, far less than the official statistics: 51\%) but were not considered as citizens (of course they didn't have the same rights and protection as city people had). Some scholars argue one of the crucial points of new-type urbanization is to ensuring the peasant-workers both the urban residence certificate (hukou) and the equal treatment of urban citizens.

\subsection{To Reform the Scale of Cities and to Increase the Number of Medium and Small Cities}

The outcome above indicates metropolis may have rejective intention against immigrant people from developing regions whose economy level and income level are far less than the big ones. Given this, increasing some medium and small cities moderately can narrow the gap of different regions, and also promote the citizenization of peasant-workers orderly. Thus the real urbanization ratio can be improved.

New medium and small cities should embrace the centre city or metropolis positioned them as satellite cites with complementary function to form urban circle and create economy of scale jointly.

\subsection{To Narrow the Income Gap between City and Country Side and to Improve the Rural Income}

As is proved above, the increase of rural income can enhance the level of urbanization. With the economy of scale brought by the process of urbanization, the added value created by peasant workers is also counted as the increment of cities' net profit. So, the local governments should not only consider immediate rewards but also put the task to improve rural income into the development of new-type urbanization.

\section{References}

[1] Wang, Z.P., Zhang, C. and Guo, L.M. (2013) Chongqing's Urbanization Rate Changes Influencing Factors-Based on Regression Analysis. Liaoning Agricultural Sciences, 5, 33-37. (in Chinese) http://www.cqvip.com/QK/94904X/201305/47558605.html

[2] Wu, J. and Shen, L.J. (2012) An Empirical Analysis of the Factors in the Route Choice of New Urbanization in Chongqing. Journal of Southwest University (Social Sciences Edition), 38, 151-155. (in Chinese) http://www.cqvip.com/QK/81271A/201202/41383543.html

[3] Guo, C.X. (2009) An Empirical Study on the Development of Urbanization and Tertiary Industry in Our Country. Special Zone Economy, 12, 290-291. (in Chinese) http://www.cqvip.com/QK/96767X/200912/32623365.html

[4] Wooldridge, J.M. (2008) Introductory Econometrics A Modern Approach. 4th Edition, Cengage Learning, 473-478

[5] Chenery, H.B. and Syrquin, M. (1975) Patterns of Development: 1950-1970. Oxford University Press, USA, 68-70. 